Original Research Article

\title{
A study of prescription pattern in the drug therapy of acne vulgaris at a tertiary care hospital in Mangalore, India
}

\author{
Pooja M. ${ }^{1 *}$, Rajendra Holla ${ }^{2}$, Girisha B. S. ${ }^{3}$, Puneeth A. ${ }^{4}$
}

${ }^{1}$ Department of Pharmacology, BGS Global Institute of Medical Sciences, Bengaluru, Karnataka, India

${ }^{2}$ Department of Pharmacology, K. S. Hegde Medical Academy, Mangaluru, Karnataka, India ${ }^{3}$ Department of Dermatology, Justice K. S. Hegde Charitable Hospital, Mangaluru, Karnataka, India

${ }^{4}$ Department of Biochemistry, Sakra World Hospital, Bengaluru, Karnataka, India

Received: 15 May 2017

Accepted: 24 June 2017

\section{*Correspondence to:}

Dr. Pooja M.,

Email: rpoojam@gmail.com

Copyright: (C) the author(s), publisher and licensee Medip Academy. This is an openaccess article distributed under the terms of the Creative Commons Attribution NonCommercial License, which permits unrestricted noncommercial use, distribution, and reproduction in any medium, provided the original work is properly cited.

\begin{abstract}
Background: Acne Vulgaris is the most common skin disorder of the pilosebaceous unit with excess sebum production, follicular epidermal hyperproliferation, inflammation and Propionibacterium acnes activity, affecting about $80 \%$ of teenagers and has considerable psychological and social consequences and physical disability. Use of established topical and oral drugs assumes paramount importance in the treatment of acne vulgaris. Therefore, periodic auditing of prescription is necessary to increase therapeutic benefit and decrease adverse effects. Aim and objectives of the study was to evaluate the pattern of prescription and its rationale in the drug therapy of acne vulgaris. To monitor the adverse effects, if any.

Methods: A prospective, hospital based, observational study. Data was collected for a period of 1 year from January 2015 to December 2015 from the outpatient records in the OPD of Dermatology at Justice K.S. Hegde Charitable Hospital, Deralakatte, Mangalore, in a specifically designed proforma.

Results: The prescription data of 346 patients were analyzed of which $45.1 \%$ were males with an average age of $21.94 \pm 0.3$ years. Among the four grades of Acne Vulgaris, Grade II $(53.17 \%)$ was more prevalent followed by Grade I $(26.58 \%)$, Grade III (13.87\%) and Grade IV (6.35\%). The number of drugs prescribed for topical use was 514 of which the most commonly prescribed drugs were Benzoyl Peroxide (19.46\%), a combination of Tretinoin and Clindamycin $(17.12 \%)$, Tretinoin alone $(12.45 \%)$, Clindamycin alone $(10.51 \%)$ etc. The number of drugs prescribed for systemic use was 98 consisting of Doxycycline (55.1\%), Azithromycin (34.7\%), Isotretinoin (6.12\%) and Erythromycin (4.08\%). Conclusions: There was rationality in most of the prescriptions giving no scope for polypharmacy.
\end{abstract}

Keywords: Acne Vulgaris, Dermatology, Rational prescription

\section{INTRODUCTION}

Skin is the largest organ of the human body. It is colonized by a diverse range of microorganisms which includes bacteria, virus, and fungi. The microorganisms are beneficial to the body and protect from the invasion of harmful pathogens. The skin is assumed as an ecosystem composed of biological and physical components forming a balance between the host and the microorganism. Disturbance in this balance is responsible for skin disorders or infections. ${ }^{1}$ Skin diseases form approximately $12.4 \%$ of all the disorders seen by the physicians. ${ }^{2}$ Skin diseases affect the patient's quality of life and psychosocial well-being. Keeping this in view, the field of 
psychodermatology has been developed because of the increased interest and understanding about the relation between skin disorders and varied psychological factors. ${ }^{3}$

Acne vulgaris is the most common skin disorder in the adolescents affecting over $80 \%$ of the teenagers. However, because of the improved treatment, the prevalence has decreased. Even though acne is not associated with severe morbidity, mortality or physical disability, it can have psychological and social consequences. ${ }^{4}$ Acne is derived from the Greek word 'acme' which means point/spot. Ancient Greek knew acne as 'tovoot' which means first growth of the beard. Therefore, development of acne was associated with puberty. ${ }^{5}$

Acne is a chronic inflammatory disease of the pilosebaceous unit described by factors such as, increased sebum production from the sebaceous glands; hormone androgen; formation of microcomedo which progresses to a comedone due to hyperkeratinization of the follicle; colonization of the follicle formed by Propionibacterium acnes leading to an inflammatory reaction. ${ }^{6}$ Acne affects the areas of the skin with dense sebaceous follicles, which is face, the upper part of the chest and the back. The prevalence and severity of acne on the face, chest and back were shown to be $92 \%, 45 \%, 61 \%$ respectively. ${ }^{7}$

Lesions in acne vulgaris may be non-inflammatory comedones or inflammatory papules, pustules, nodules, and cysts. The severity of acne vulgaris is measured by simple grading based on clinical examination, lesion counting, photography, video microscopy and measurement of sebum production. Carmen Thomas of Philadelphia was the first person to use a scoring system for the assessment of acne vulgaris. Several systems for grading the severity of acne currently exist. ${ }^{8}$

Acne vulgaris was graded by Indian authors using a simple grading system, which classifies acne vulgaris into four grades as follows:

- Grade 1: Comedones and occasional papules.

- Grade 2: Papules with comedones and few pustules.

- Grade 3: Predominant pustules with nodules and abscesses.

- $\quad$ Grade 4: Mainly cysts and abscesses associated with widespread scarring.

The Combined Acne Severity Classification comprised of three categories:

- Mild acne: less than 20 comedones, or less than 15 inflammatory lesions or a total lesion count below 30 .

- Moderate acne: 20-100 comedones, or 15-50 inflammatory lesions or a total lesion count of 30125.

- $\quad$ Severe acne: more than 5 cysts, or comedone count more than 100 , or a total inflammatory count above 50 , or a total lesion count above 125 .
According to the recent proposal from the US FDA, grading of acne can be stated as follows:

- $\quad 0=$ Normal, clear skin without evidence of acne vulgaris

- 1 = Skin is almost clear: few non-inflammatory lesions present, with rare non-inflamed papules (papules must be resolving and may be hyperpigmented, though not pink- red)

- $\quad 2$ = Few non-inflammatory lesions are present, with some inflammatory lesions which include papules and pustules but not nodulocystic lesions.

- 3 = Non-inflammatory lesions predominate with evident multiple inflammatory lesions. Comedones, papules, and pustules present with or without few nodulocystic lesions.

- $\quad 4$ = Inflammatory lesions are more dominant: many comedones and papules/pustules, a few nodulocystic lesions may or may not be present.

- 5 = Highly inflamed lesions predominate: variable number of comedones, many papules, pustules and nodulocystic lesions. ${ }^{9,10}$

Treatment of acne vulgaris includes both topical therapy as well as systemic antibiotics. Topical agents include Retinoids, Benzoyl Peroxide, Clindamycin which are known to reduce the obstruction in the follicle, prevent Propionibacterium resistance. Systemic antibiotics used are Doxycycline, Erythromycin, and Azithromycin. Oral Isotretinoin is approved for the treatment of severe recalcitrant nodular acne. It is a potent drug, but it must be avoided in female patients of childbearing age group because of its teratogenic properties. Hormonal agents like Estrogen-containing oral contraceptives, oral antiandrogens such as Spironolactone, Cyproterone acetate, and Flutamide are found to be useful in the treatment of acne. Other miscellaneous therapies are acupuncture, avoiding diet with high glycemic index, intralesional corticosteroid injections, Glycolic acid and Salicylic acid based peeling, comedone removal, microdermabrasion and use of Tea tree oil and other medicinal plant products. ${ }^{6,11,12}$

Prescription forms an important tool in the treatment of a patient's illness so as to provide maximum therapeutic effect with decreased adverse effects. The irrational prescription is a global issue resulting in ineffective and unsafe treatment, exacerbation or prolongation of illness, distress, and harm to the patient and economical burden. Rational use of drugs will ensure that patients receive appropriate medications to their clinical requirements, in doses that meet their own individual needs for an adequate period of time, at the lowest cost to them and their community. ${ }^{13,14}$

Periodic auditing of the prescription will ensure that the drugs prescribed to the patient are rational and not causing unnecessary burden either in terms of cost or side effects. The study of prescribing patterns is a part of the medical audit which seeks to monitor, evaluate and suggest 
modifications in prescribing practices to make medical care rational and cost-effective. ${ }^{15,16}$

Therefore, the present study envisages analysis of the data, evaluation of the prescription pattern, extent, rationality, and frequency of drugs in the treatment of acne vulgaris for the information of the esteemed medical fraternity.

\section{METHODS}

It was a prospective, observational study. The study was undertaken for a period of 12 months from January 2015 to December 2015.

The study was conducted in the Outpatient Department of the Dermatology Department of Justice K. S. Hegde Charitable Hospital, Deralakatte, Mangalore, which is a teaching hospital, with the support and co-operation of the Dermatology Department.

\section{Inclusion criteria}

Patients who report to the Outpatient Department of Dermatology of Justice K. S. Hegde Charitable Hospital with:

- $\quad$ Age 12 years or more of either gender.

- Diagnosed with Acne Vulgaris Grade I to Grade IV.

\section{Exclusion criteria}

The patients excluded from the study include:

- Those who are hypersensitive to antibiotics.

- Pregnant and lactating women.

- Drug-induced acne.

\section{Study procedure}

The study was carried out at the Outpatient Department of the Dermatology Department after acquiring permission from the Institutional Ethics Committee and taking formal permission from the Head of the Department of Dermatology. Patients treated for Acne Vulgaris of different grading were enrolled in the study considering the Inclusion and Exclusion criteria.

\section{Data collection}

The relevant data was collected in person by the investigator from the medical case records of the patients pertaining to the Dermatology Department at Justice K. S. Hegde Charitable Hospital, Deralakatte, Mangalore.

The data was collected in a specially designed proforma which included the following details:

\section{Demographic data:}

- Name, age, gender, address.
2. Disease data:

- Diagnosis of the disease with grading.

3. Data pertaining to the drug therapy which included:

- Drug/ drugs prescribed, route of administration, drug formulations, dose, and frequency of administration and duration of treatment.

\section{Statistical analysis}

The collected data was coded into and analyzed using SPSS software (version 16.0) and represented as number and percentage.

\section{RESULTS}

A total of 346 prescriptions for patients diagnosed with Acne Vulgaris in the Outpatient Department of the Dermatology Department of Justice K. S. Hegde Medical Academy, Deralakatte, Mangalore were screened based on the Inclusion and Exclusion criteria, over a period of 12 months. Of the total 346 patients, $156(45.1 \%)$ and 190 $(54.9 \%)$ were males and females respectively. The average age of all the patients was $21.94 \pm 5.3$ years.

Among the four grades of Acne Vulgaris, the most commonly reported grade was Grade II (184 patients, $53.17 \%$ ), followed by Grade I (92 patients, 26.58\%) and Grade III (48 patients, 13.87\%) (Table 1).

Table 1: Prevalence of the four grades of Acne Vulgaris among the patients.

\begin{tabular}{|llll|}
\hline $\begin{array}{l}\text { Grade of } \\
\text { acne vulgaris }\end{array}$ & $\begin{array}{l}\text { Males } \\
(\mathbf{n})\end{array}$ & $\begin{array}{l}\text { Females } \\
(\mathbf{n})\end{array}$ & $\begin{array}{l}\text { Total } \\
\mathbf{n}(\boldsymbol{\%})\end{array}$ \\
\hline I & 34 & 58 & $92(26.58)$ \\
\hline II & 84 & 100 & $184(53.17)$ \\
\hline III & 20 & 28 & $48(13.87)$ \\
\hline IV & 18 & 4 & $22(6.35)$ \\
\hline Total & 156 & 190 & $346(100)$ \\
\hline
\end{tabular}

Table 2: Frequency of the drugs prescribed per patient.

\begin{tabular}{|lll|}
\hline Number of drugs & $\begin{array}{l}\text { Number of } \\
\text { prescriptions }\end{array}$ & Percentage \\
\hline 1 & 142 & 41 \\
\hline 2 & 146 & 42.2 \\
\hline 3 & 54 & 15.6 \\
\hline 4 & 4 & 1.2 \\
\hline Total & 346 & 100 \\
\hline
\end{tabular}

Out of the 346 prescriptions, the total number of drugs prescribed was 612 . The number of drugs prescribed per patient ranged from 1 to 4 . The average number of drugs per prescription was 1.77 . However, 146 patients (42.2\%) received 2 drugs per prescription while 142 patients 
(26.6\%) received monotherapy (Table 2). 604 (98.7\%) drugs were prescribed in their brand names. 514 drugs $(83.99 \%)$ were prescribed for the topical application while 98 drugs $(16.01 \%)$ were prescribed for systemic use.

Out of the 346 prescriptions and among the 514 drugs prescribed for topical use, the highest prescribed was Benzoyl Peroxide (100 prescriptions, 19.46\%), followed by a combination of Tretinoin and Clindamycin (88 prescriptions, $17.12 \%$ ), and Facewashes (80 prescriptions, $15.56 \%$ ) and Tretinoin (64 prescriptions, $12.45 \%$ ). Of the 514 topically prescribed drugs for Acne Vulgaris, 80 drugs $(15.56 \%)$ were Facewash. Among these, the most commonly prescribed facewashes contained Salicylic acid, (28 drugs, 35\%) and a combination of Glycolic acid and Aloe Vera, (28 drugs, 35\%) (Table 3) (Table 4).

Table 3: Frequency of the most commonly prescribed drugs for topical use.

\begin{tabular}{|lll|}
\hline Topical drugs & $\begin{array}{l}\text { Number of } \\
\text { prescriptions }\end{array}$ & Percentage \\
\hline Benzoyl peroxide & 100 & 19.46 \\
\hline $\begin{array}{l}\text { Tretinoin+ } \\
\text { clindamycin }\end{array}$ & 88 & 17.12 \\
\hline Facewash & 80 & 15.56 \\
\hline Tretinoin & 64 & 12.45 \\
\hline Clindamycin & 54 & 10.51 \\
\hline $\begin{array}{l}\text { Adapalene+ } \\
\text { benzoyl peroxide }\end{array}$ & 40 & 7.78 \\
\hline $\begin{array}{l}\text { Benzoyl peroxide+ } \\
\text { clindamycin }\end{array}$ & 26 & 5.06 \\
\hline Sunscreen & 16 & 3.11 \\
\hline Azelaic acid & 12 & 2.33 \\
\hline Adapalene & 8 & 1.56 \\
\hline $\begin{array}{l}\text { Clindamycin+ } \\
\text { nicotinamide }\end{array}$ & 6 & 1.17 \\
\hline Mupirocin & 6 & 1.17 \\
\hline Aloe vera & 6 & 1.17 \\
\hline $\begin{array}{l}\text { Fusidic acid+ } \\
\text { betamethasone }\end{array}$ & 4 & 0.78 \\
\hline Peeling & 4 & 0.78 \\
\hline Total & 514 & 100 \\
\hline
\end{tabular}

Table 4: Percentage of most commonly used facewash.

\begin{tabular}{|lll|}
\hline $\begin{array}{l}\text { Ingredient in the } \\
\text { facewash }\end{array}$ & $\begin{array}{l}\text { Number of } \\
\text { prescriptions }\end{array}$ & Percentage \\
\hline Salicylic acid & 28 & 35 \\
\hline $\begin{array}{l}\text { Glycolic acid+aloe } \\
\text { vera }\end{array}$ & 28 & 35 \\
\hline Vitamin C & 24 & 30 \\
\hline Total & 80 & 100 \\
\hline
\end{tabular}

Out of the 346 prescriptions and among the 98 drugs prescribed for systemic use, the most commonly prescribed drug was Doxycycline (54 prescriptions,
$55.10 \%$ ), followed by Azithromycin (34 prescriptions, $34.7 \%$ ) and Isotretinoin (6 prescriptions, 6.12\%) (Table 5).

Table 5: Frequency of most commonly used drugs for systemic use.

\begin{tabular}{|lll|}
\hline Systemic drugs & $\begin{array}{l}\text { Number of } \\
\text { prescriptions }\end{array}$ & Percentage \\
\hline Doxycycline & 54 & 55.10 \\
\hline Azithromycin & 34 & 34.7 \\
\hline Isotretinoin & 6 & 6.12 \\
\hline Erythromycin & 4 & 4.08 \\
\hline Total & 98 & 100 \\
\hline
\end{tabular}

Out of the 612 drugs prescribed in 346 prescriptions, the total number of Fixed Dose Combinations prescribed was $164(26.8 \%)$. Among these, the most commonly prescribed FDC was a combination of Tretinoin and Clindamycin (88 prescriptions, $53.66 \%$ ) followed by a combination of Benzoyl Peroxide and Adapalene (40 prescriptions, 24.4\%) and Benzoyl Peroxide and Clindamycin (26 prescriptions, $15.85 \%$ ) (Table 6).

Table 6: Number of fixed dose combinations used in the treatment of acne vulgaris.

\begin{tabular}{|lll|}
\hline $\begin{array}{l}\text { Fixed dose } \\
\text { combination }\end{array}$ & $\begin{array}{l}\text { Number of } \\
\text { prescriptions }\end{array}$ & Percentage \\
\hline $\begin{array}{l}\text { Tretinoin }+ \\
\text { clindamycin }\end{array}$ & 88 & 53.66 \\
\hline $\begin{array}{l}\text { Benzoyl peroxide }+ \\
\text { adapalene }\end{array}$ & 40 & 24.4 \\
\hline $\begin{array}{l}\text { Benzoyl peroxide }+ \\
\text { clindamycin }\end{array}$ & 26 & 15.85 \\
\hline $\begin{array}{l}\text { Clindamycin }+ \\
\text { nicotinamide }\end{array}$ & 6 & 3.66 \\
\hline $\begin{array}{l}\text { Fusidic acid }+ \\
\text { betamethasone }\end{array}$ & 4 & 2.44 \\
\hline Total & 164 & 100 \\
\hline
\end{tabular}

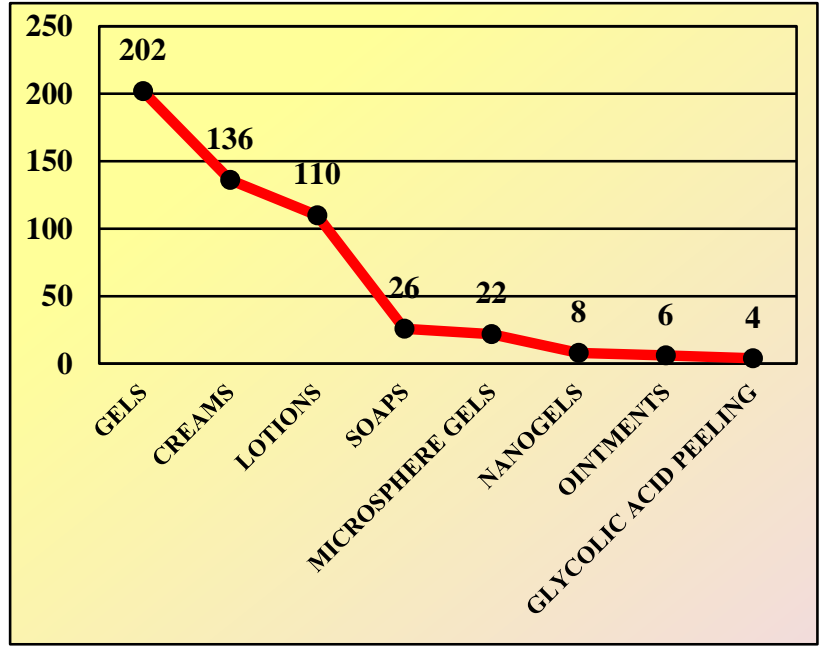

Figure 1: Frequency of different formulations of drugs for topical use. 


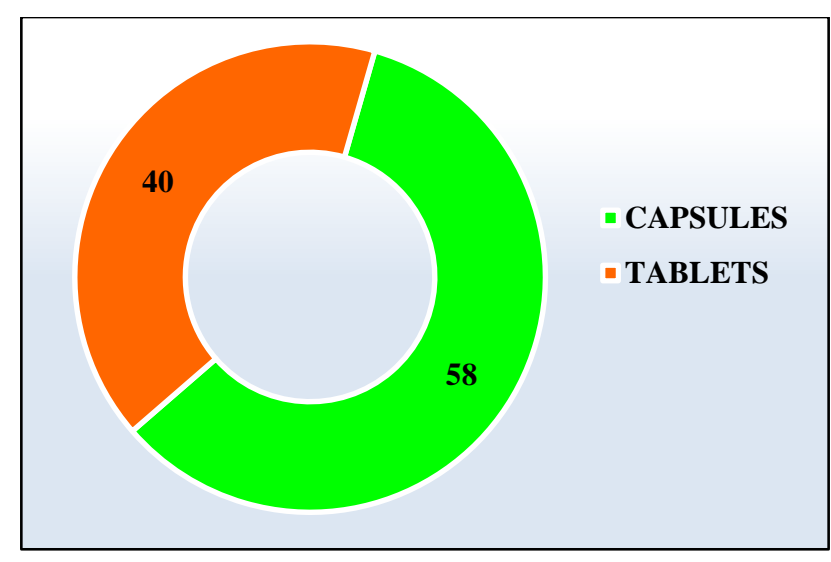

Figure 2: Frequency of different formulations of drugs used systemically.

As mentioned earlier, out of the 612 drugs prescribed, 514 were prescribed for topical use and the rest 98 were prescribed for systemic use. The most common formulation of the topical drug was gels (202 drugs, $39.3 \%$ ) followed by creams (136 drugs, 26.46\%) and lotions (110 drugs, 21.4\%). Likewise, out of the 98 drugs prescribed for systemic use, 58 drugs $(59.18 \%)$ were prescribed in the form of capsules while the remaining 40 drugs $(40.82 \%)$ were prescribed in the form of Tablets. (Figure 1, 2).

Table 7: The WHO core prescribing indicators.

\begin{tabular}{|ll|}
\hline WHO Core prescribing indicator & Percentage \\
\hline Average number of drugs per encounter & 1.77 \\
\hline $\begin{array}{l}\text { Percentage of drugs prescribed in } \\
\text { generic names }\end{array}$ & $1.3 \%$ \\
\hline Percentage of antibiotics prescribed & $45.09 \%$ \\
\hline $\begin{array}{l}\text { Percentage of prescriptions with an } \\
\text { injection }\end{array}$ & NIL \\
\hline $\begin{array}{l}\text { Percentage of drugs taken from the } \\
\text { National List of Essential Medicines }\end{array}$ & $59.15 \%$ \\
\hline
\end{tabular}

Table 8: Drugs taken from the National list of essential medicine.

\begin{tabular}{|lll|}
\hline Drug from NLEM & $\begin{array}{l}\text { Number of } \\
\text { prescriptions }\end{array}$ & \begin{tabular}{l} 
Percentage \\
\hline Benzoyl peroxide
\end{tabular} \\
\hline Tretinoin & 64 & 27.62 \\
\hline Doxycycline & 54 & 17.68 \\
\hline Clindamycin & 54 & 14.91 \\
\hline Azithromycin & 34 & 14.91 \\
\hline Salicylic acid & 28 & 9.4 \\
\hline Vitamin C & 24 & 7.73 \\
\hline Erythromycin & 4 & 6.63 \\
\hline Total & 362 & 1.1 \\
\hline
\end{tabular}

Table 7 shows the core prescribing indicators while Table 8 explains the drugs taken from the National List of Essential Medicines. Among the 612 drugs prescribed in the 346 prescriptions, the number of drugs taken from the National List of Essential Medicines was 362 (59.15\%).

\section{DISCUSSION}

The prescription pattern forms a major tool in the assessment of the quality of patient care accorded in a health care system. This study was undertaken to study the prescription pattern in the drug therapy of Acne Vulgaris.

We screened prescriptions of 346 patients who reported with Acne Vulgaris at the Outpatient Department of the Dermatology Department of Justice K. S. Hegde Charitable Hospital, Mangalore over a period of 1 year.

Among the 346 patients, the number of males and females were $156(45.1 \%)$ and $190(54.9 \%)$ respectively with Male: Female ratio being 1: 1.21. The mean age group of the patients was $21.94 \pm 5.3$ years. This is in contrast with the findings of Santosh Kumar et al who reported the Male: Female ratio to be 1:1.07 with the mean age group being $21.67 \pm 0.51$ years. $^{17}$

Among the four grades of Acne Vulgaris, we assessed that Grade II was more prevalent (184 patients, 53.17\%) followed by Grade I (92 patients, $26.58 \%$ ) and Grade III (22 patients, $6.35 \%$ ). Authors conducted a similar study in which Grade II was most common followed by Grade III and Grade I respectively. ${ }^{18}$

Out of the 346 prescriptions, the total number of drugs prescribed was 612 and the number of drugs per prescription was 1.77 while the other studies have much higher values like 5.13, 4.76, 3.26 and 2.7 drugs per prescription respectively. ${ }^{17,19-21}$ This explains the tendency of polypharmacy for the symptomatic treatment of Acne Vulgaris. Concerns with Polypharmacy include increased the risk of side effects, drug-drug interactions, and increased financial burden for the patients and also a lack of strategies for the guidance of this practice. ${ }^{22}$

In the study, $98.7 \%$ of the drugs were prescribed in their brand names while other studies have been consistent with $100 \%$ drugs being prescribed in their brand names. The number of patients who received monotherapy was 142 $(41.04 \%)$ and those who received polytherapy were 204 $(58.96 \%)$. The number of Fixed Dose Combinations (FDC) were 164 (26.79\%). In contrast to this data, authors have reported that in their study $6.2 \%$ patients received monotherapy and $93.8 \%$ received polytherapy. Also, in comparison to the study conducted by Santosh et al, the number of Fixed Dose Combinations were only 3.08\% while it is much higher in our study. Fixed-dose combinations are of value when they are developed on the basis of rational Pharmacokinetic and Pharmacodynamics criteria and the combination should produce a synergistic effect and should not possess any supra-additive toxic effect. FDC's are also convenient and have better patient compliance. ${ }^{17,18,23,24}$ 
Out of the 346 prescriptions and 612 drugs screened, 514 drugs (83.99\%) were prescribed for topical application and 98 drugs $(16.01 \%)$ were for systemic use. This was not in accordance with the report given authors which mentioned the percentage of drugs prescribed for topical and systemic use was $52.56 \%$ and $47.44 \%$ respectively. ${ }^{18}$

As mentioned by Kraft et al, the first line of treatment for different stages of acne is mentioned below:

- Mild comedonal acne: Topical Retinoids,

- Mild inflammatory acne: Topical retinoid/ Benzoyl peroxide/ Clindamycin/ Erythromycin or FDC's

- Moderate acne: Oral Tetracyclines/ Erythromycin/ Trimethoprim+ Sulfamethoxazole; Topical Retinoid \pm Benzoyl Peroxide.

- $\quad$ Severe Acne: Oral Isotretinoin. ${ }^{25}$

Among the drugs prescribed for topical use, the most common formulations were gels (202 drugs, 39.3\%) followed by creams (136 drugs, 26.46\%) and lotions (110 drugs, $21.4 \%$ ) and the most common formulation of drugs for systemic use was capsules (58 drugs, 59.18\%) followed by tablets (40 drugs, $40.82 \%$ ). The results were different when compared with a study published by Anuj et al. which reported that majority of topical formulations were in the form of creams followed by lotions and gel. In the case of systemic drugs, tablets were more prescribed than capsules. ${ }^{19}$ Out of 612 drugs, 362 drugs (59.15\%) were taken from the National List of Essential Medicines (NLEM, 2015). In contrast to this, $39.92 \%$ of the drugs were prescribed from the NLEM as mentioned by Santosh et al in their study. ${ }^{17,26}$

\section{CONCLUSION}

Acne Vulgaris is one of the most common skin disorders and forms a major issue because of its impact on the quality of life and psychosocial well-being. With increasing concerns about the rational usage of drugs and the need for auditing the prescriptions and also for the improvement of the patient care systems, this study was undertaken to document and analyze the prescribing patterns for Acne Vulgaris by the dermatologists.

We have found that the therapy was given based on the clinical knowledge and experience and was empirical but rational in accordance with the available literature.

\section{ACKNOWLEDGEMENTS}

Authors would like to express their humble gratitude to the patients who participated in our study. Also, they are thankful to the head of the institution for permitting us to carry out our study.

Funding: No funding sources Conflict of interest: None declared

Ethical approval: The study was approved by the Institutional Ethics Committee

\section{REFERENCES}

1. The skin microbiome. Nat Rev Microbiol. 2013;9(4):244-53.

2. Verhoeven EWM, Kraaimaat FW, Weel C Van, Duller P, Hoogen HJM Van Den, Schers HJ, et al. Skin diseases in family medicine. Prevalence and health care use. Ann Fam Med. 2008;6(4):349-54.

3. Barankin B, DeKoven J. Psychosocial effect of common skin diseases. Can Fam Physician. 2002;48:712-6.

4. Purdy S, Langston J, Tait L. Presentation and management of acne in primary care: a retrospective cohort study. Br J Gen Pract. 2003;53(492):525-9.

5. Tabasum H, Ahmad T, Anjum F, Rehman H. The Historic Panorama of Acne Vulgaris. 2013;2(1):99104.

6. Titus S, Hodge J. Diagnosis and treatment of acne. Postgrad Med. 1955;17:205-9.

7. Ramli R, Malik AS, Hani AFM, Jamil A. Acne analysis, grading and computational assessment methods: An overview. Ski Res Technol. 2012;18(1):1-14.

8. Thappa D, Adityan B, Kumari R. Scoring systems in acne vulgaris. Indian $\mathrm{J}$ Dermatol Venereol Leprol. 2009;75(3):323.

9. Hp L, Acad A, Wj C, Sc B, Jb L, Wj C, et al. Acne Global Severity Scale. 2002.

10. Tan J. Current Measures for the Evaluation of Acne Severity. Expert Reviews Dermatology. 2008;3(5):595-603.

11. Purdy S, Deberker D. Acne vulgaris Search date June 2007 Skin disorders Acne vulgaris. Clin Evid (Online). 2008;05(1714):1-34.

12. Strauss JS, Krowchuk DP, Leyden JJ, Lucky AW, Shalita AR, Siegfried EC, et al. Guidelines of care for acne vulgaris management. J Am Acad Dermatol. 2007;56(4):651-63.

13. Desalegn AA. Assessment of drug use pattern using WHO prescribing indicators at Hawassa University teaching and referral hospital, south Ethiopia: a crosssectional study. BMC Health Serv Res. 2013;13(1):16.

14. Tunger O, Karakaya Y, Cetin CB, Dinc G, Borand H. Rational antibiotic use. J Infect Dev Ctries. 2009;3(2):88-93.

15. Shankar PR, Upadhyay DK, Subish P, Dubey AK, Mishra P. Prescribing patterns among paediatric inpatients in a teaching hospital in western Nepal. Singapore Med J. 2006;47(4):261-5.

16. Potharaju HR, Kabra SG. Prescription audit of outpatient attendees of secondary level government hospitals in Maharashtra. Indian J Pharmacol. 2011 Apr;43(2):150-6.

17. Santosh K, Shaktibala D, Mirza AB, Anil KM, Mohammed A, Saubhagya S. Drug utilization pattern in Acne Vulgaris in Skin Outpatients department of a tertiary care teaching hospital at Dehradun, Uttarakhand. Int J Med Sci Public Heal. 2014;3(7):36. 
18. Nibedita P, Jena M, Panda M, Dash M. A Study on the Prescribing Pattern of Drugs for Acne in a Tertiary Care Teaching Hospital in Odisha. J Clin Diagnostic Res. 2015;9(3):4-6.

19. Anuj KP, Subodh K, Manish K, Lalit M, Harihar D. Study of Drug Utilization Pattern for Skin Diseases in Dermatology OPD of an Indian Tertiary Care Hospital: A Prescription Survey. J Clin Diagnostic Res. 2016;10(2):1-5.

20. Gautam CS, Saha L, Fixed Dose Drug Combinations (FDC's): rational or irrational: a view point, Br J Clin Pharmacol. 2007;65(5):795-6.

21. Gautam CS, Aditya S, Irrational drug combinations: Need to Sensitise undergraduates: Ind J Pharmacol. 2006;38:167-70.

22. Murray MD, Kroenke K. Polypharmacy and medication adherence: small steps on a long road. J Gen Intern Med. 2001;16:137-9.
23. Tripathi KD. Essential of Medical Pharmacology. $7^{\text {th }}$ Ed. New Delhi; 2013:61-62.

24. Poudel A, Palaian S, Shankar PR, Jayasekara J, Izham MIM, Irrational Fixed dose combinations in Nepal: Need for intervention. Kathmandu University Medical Journal. 2008;6(3):399-405.

25. John K, Anatoli F. Management of acne. Can Med Assoc J. 2011;183(7):430-5.

26. National List of Essential Medicines. In 2015:1-117.

Cite this article as: Pooja M, Holla R, Girisha BS, Puneeth A. A study of prescription pattern in the drug therapy of acne vulgaris at a tertiary care hospital in Mangalore, India. Int J Basic Clin Pharmacol 2018;7:80-6. 